\title{
Ishikawa Diagram dan Failure Mode Effect Analysis (FMEA) sebagai Metode yang sering digunakan dalam Manajemen Risiko Mutu di Industri
}

\author{
Yasarah Hisprastin ${ }^{*}$, , Ida Musfiroh² \\ 1Program Studi Profesi Apoteker, Fakultas Farmasi, Universitas Padjadjaran, \\ 2Departemen Analisis Farmasi dan Kimia Medisinal, Fakultas Farmasi, Universitas Padjadjaran, \\ *E-mail: yasarah15001@mail.unpad.ac.id \\ (Submit 28/4/2020, Revisi 9/5/2020, Diterima 20/8/2020, Terbit 29/10/2020)
}

\begin{abstract}
Abstrak
Kualitas produk harus dijaga sepanjang siklus hidup produk sehingga kualitasnya tetap konsisten dan aman untuk digunakan. Salah satu metode untuk menjaga kualitas produk yaitu dengan manajemen risiko mutu. Manajemen risiko yang efektif yaitu dapat memastikan kualitas produk terjamin secara proaktif dan reaktif selama pengembangan, proses produksi, hingga beredarnya produk di pasaran. Metode yang sering digunakan dalam manajemen risiko adalah Ishikawa Diagram dan Failure Mode Effect Analysis (FMEA) karena dapat memberikan banyak informasi mengenai penyebab masalah dan akibatnya serta mudah digunakan. Penulisan ini berdasarkan studi literatur melalui buku dan jurnal penelitian yang telah diterbitkan dari 2009 hingga sekarang dan dapat diakses secara online di website jurnal nasional dan internasional mengenai Ishikawa Diagram dan FMEA sebagai metode untuk manajemen risiko. Tujuan dari penulisan ini adalah untuk menelaah kedua metode tersebut dalam manajemen resiko sehingga dapat digunakan secara proaktif dan reaktif. Hasil dari menggunakan kedua metode adalah dapat memfasilitasi keputusan yang lebih baik, memberikan jaminan yang lebih besar untuk menghadapi risiko potensial, serta dapat memengaruhi tingkat pengawasan proses produksi maupun produk akhir. Dapat disimpulkan dengan menggunakan metode dalam manajemen risiko mutu dapat mengendalikan risiko secara efisien.
\end{abstract}

Kata kunci: Manajemen risiko, Failure Mode Effect Analysis, dan ishikawa diagram

\section{Pendahuluan}

Penting untuk memahami bahwa kualitas produk harus dijaga sepanjang siklus hidup produk sehingga kualitas produk tetap konsisten. Untuk menjaga kualitas produk salah satunya dengan manajemen risiko mutu ${ }^{9}$. Ada dua prinsip utama dalam manajemen risiko mutu yaitu bahwa evaluasi risiko terhadap mutu hendaklah mengutamakan keamanan pasien serta tingkat usaha, kepatuhan, dan dokumentasi pengkajian risiko mutu hendaklah setara dengan tingkat risiko yang ditimbulkan ${ }^{1}$. 
Manajemen risiko yang efektif dapat memastikan kualitas produk sampai ke tangan konsumen terjamin. Apabila terjadi keluhan, industri secara proaktif dan reaktif mampu memperbaiki selama proses produksi sampai keluhan terhadap produk terselesaikan ${ }^{10}$. Dengan mengembangkan manajemen risiko mutu yang efektif maka dapat meminimalkan risiko, meningkatkan kualitas produk dan mengembangkan sistem supaya kemungkinan risiko dan mitigasi risiko tersebut teridentifikasi ${ }^{7}$.

Pengambilan keputusan terbaik diperoleh melalui manajemen risiko yang terdokumentasi, transparan, dan mudah diterapkan ${ }^{6}$. Berbagai metode dalam pengelolaan risiko berkaitan dengan jaminan kualitas, tetapi sebagian metode yang tersedia hanya cocok untuk praktik tertentu, dan tidak dapat digunakan di semua tempat ${ }^{8}$. Metode yang popular digunakan di industri adalah Ishikawa diagram dan FMEA karena mampu memberikan banyak informasi mengenai penyebab masalah dan dampaknya ${ }^{16}$.

FMEA adalah metode manajemen risiko proaktif untuk identifikasi semua potensi kegagalan yang mungkin terjadi dalam rancangan, proses produksi, maupun produk ${ }^{21}$. Sedangkan Ishikawa diagram merupakan metode manajemen risiko reaktif untuk indentifikasi penyebab potensial masalah karena penyimpangan selama proses produksi atau keluhan terkait produk. Ishikawa diagram sering juga disebut sebagai diagram tulang ikan (fishbone diagram) atau diagram sebab akibat. Ishikawa diagram sering digunakan di industri karena metode yang user friendly4.

\section{Metode}

Metode yang digunakan dalam penulisan review artikel ini adalah studi literatur dengan sumber primer berupa buku dan jurnal penelitian yang telah dipublikasi secara online di website jurnal nasional dan internasional. Kriteria inklusi review artikel adalah jurnal yang memuat informasi terkait Ishikawa Diagram dan Failure Mode Effect Analysis (FMEA) sebagai salah satu metode untuk manajemen risiko. Sedangkan kriteria eksklusi review artikel adalah buku dan jurnal yang dipublikasi sebelum tahun

\section{Pembahasan}

\section{FMEA}

Metode FMEA merupakan salah satu metode penilaian risiko proaktif yang paling dikenal dan banyak digunakan di industri ${ }^{17}$. Failure Mode adalah kegagalan suatu produk atau proses sesuai dengan fungsinya atau penyebab kegagalan sedangkan 
Effect Analysis adalah menganalisis akibat yang mungkin terjadi dari setiap kegagalan ${ }^{15}$. Oleh karena itu, FMEA merupakan metode untuk mengidentifikasi semua potensi kegagalan yang mungkin terjadi dalam rancangan dan/atau proses produksi hingga produk dihasilkan, serta menganalisis akibat dari setiap kegagalan ${ }^{4}$. Secara umum terdapat dua tipe FMEA yaitu FMEA desain dan FMEA proses ${ }^{19}$. FMEA desain, observasi difokuskan pada rancangan produk sedangkan FMEA proses observasi difokuskan pada aktivitas proses produksi ${ }^{25}$. Tujuan penggunaan FMEA adalah menentukan tindakan untuk menghilangkan atau mengurangi risiko bahaya terutama untuk prioritas risiko tertinggi. Prioritas risiko ditentukan dari nilai risiko dalam bentuk Risk Priority Number (RPN) dengan beberapa faktor. Risiko kegagalan dan akibatnya ditentukan oleh tiga faktor yaitu ${ }^{14,24}$ :

1. Tingkat keparahan dari kegagalan jika terjadi (severity)

2. Frekuensi kegagalan yang terjadi (occurrence)

3. Kemungkinan kegagalan untuk terdeteksi sebelum kejadian (detection)

Manfaat dalam menggunakan metode FMEA diantaranya dapat menentukan prioritas untuk setiap tindakan perbaikan, menyediakan dokumen yang lengkap tentang perubahan proses untuk membantu perkembangan selanjutnya, meningkatkan kualias, keandalan, dan keamanan produk dan meminimalkan waktu dan biaya ${ }^{3}$. Metode FMEA memerlukan brainstorming oleh karena itu, perlu dibentuk tim FMEA dengan tujuan untuk memberikan perspektif dan experience yang berbeda dari masing-masing individu ${ }^{20}$. Tim FMEA hanya dibentuk jika dibutuhkan dan anggotanya mewakili dari setiap bidang yang akan dibahas. FMEA dikerjakan menggunakan FMEA Worksheet yang dapat dilihat pada Tabel $1^{10}$

Tabel 1. FMEA Worksheet ${ }^{10}$

\begin{tabular}{|c|c|c|c|c|c|c|c|c|c|c|c|c|c|c|}
\hline \multirow[b]{2}{*}{$\begin{array}{l}\text { Component } \\
\text { and Function }\end{array}$} & \multirow[b]{2}{*}{$\begin{array}{l}\text { Failure } \\
\text { Mode }\end{array}$} & \multirow[b]{2}{*}{$\begin{array}{l}\text { Foilure } \\
\text { Effect }\end{array}$} & \multirow{2}{*}{ 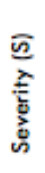 } & \multirow[b]{2}{*}{$\begin{array}{l}\text { Failure } \\
\text { Cause }\end{array}$} & \multirow{2}{*}{$\begin{array}{l}\widehat{\mathrm{g}} \\
\mathrm{g} \\
\mathrm{E} \\
\mathrm{b} \\
\mathrm{Z} \\
\mathrm{g} \\
\mathrm{O}\end{array}$} & \multirow[b]{2}{*}{$\begin{array}{l}\text { Current } \\
\text { Control }\end{array}$} & \multirow{2}{*}{ 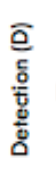 } & \multirow[b]{2}{*}{ RPN } & \multirow[b]{2}{*}{$\begin{array}{c}\text { Recommedation } \\
\text { Action }\end{array}$} & \multirow[b]{2}{*}{$\begin{array}{l}\text { Action } \\
\text { Taken }\end{array}$} & \multicolumn{4}{|c|}{ Action Result } \\
\hline & & & & & & & & & & & $\begin{array}{l}\text { Action } \\
\text { Result }\end{array}$ & $s$ & $O D$ & RPN \\
\hline
\end{tabular}

Langkah-langkah dalam mengerjakan proses FMEA sebagai berikut ${ }^{18}$ :

1. Melakukan kajian proses atau produk

Tim mengkaji dari blueprint untuk produk FMEA atau flowchart untuk proses FMEA. Untuk produk, tim harus secara langsung melihat produk atau prototipe produk. Sedangkan untuk proses, tim harus menelusuri proses kegiatan produksi untuk mengetahui alur dan proses yang terjadi.

\section{Tim FMEA melakukan brainstorming}

Brainstorming menggunakan pendekatan round-robin yaitu pendekatan yang setiap anggota diharuskan menyampaikan ide ${ }^{22}$. Ide yang diberikan berkaitan dengan penyebab kegagalan produk atau proses yang dibahas. Ide-ide dikategorikan berdasarkan tipe kegagalan atau tingkat keparahan kegagalan.

3. Menentukan tingkat keparahan (level severity)

Tingkat keparahan merupakan perkiraan keparahan akibat jika kegagalan terjadi 
dalam bentuk skor. Faktor-faktor yang berperan dalam menentukan tingkat keparahan untuk analisis produk adalah akibat terhadap pelanggan sedangkan untuk analisis proses adalah akibat terhadap prosesnya.

4. Menentukan tingkat kejadian (level occurrence)

Tingkat kejadian merupakan frekuensi kegagalan yang terjadi dalam bentuk skor. Tingkat kejadian ditentukan dengan melihat track record kegagalan selama satu tahun terakhir.

5. Menentukan tingkat deteksi (level detection)

Tingkat deteksi merupakan seberapa besar kemungkinan dapat mendeteksi kegagalan atau akibat dari kegagalan dalam bentuk skor. Kunci utamanya dengan mengidentifikasi kontrol saat ini yang dapat mendeteksi kegagalan atau efek akibat kegagalan.

6. Menentukan RPN

RPN merupakan hasil perkalian masing-masing skor severity, occurrence dan detection. RPN berfungsi sebagai tolak ukur untuk perbandingan dengan RPN total yang direvisi setelah tindakan yang direkomendasikan dilakukan

7. Menentukan prioritas kegagalan untuk tindakan

Tindakan berdasarkan tingkat prioritas kegagalan melalui nilai RPN.

8. Melakukan tindakan untuk mengurangi risiko

Tindakan dilakukan berdasarkan rekomendasi tindakan dari tim FMEA.

9. Menghitung kembali nilai RPN setelah tindakan

Setelah melakukan tindakan, skor baru untuk level severity, occurrence, dan detection harus ditentukan. Nilai RPN yang baru disebut sebagai Resulting RPN. Tidak ada target RPN untuk metode FMEA. Tim FMEA dan perusahaan yang memutuskan seberapa jauh tim harus melakukan perubahan.

Berikut beberapa hasil penggunaan Ishikawa diagram yang ditampilkan dalam Tabel 2 .

\section{Ishikawa Diagram}

Ishikawa diagram pertama kali diperkenalkan oleh Kaoru Ishikawa dan termasuk sebagai salah satu dari tujuh metode dasar dalam pengendalian kualitas ${ }^{12}$. Ishikawa diagram merupakan metode manajemen risiko reaktif dengan mengindentifikasi penyebab potensial dari suatu masalah untuk menemukan akar penyebab masalah melalui sesi brainstorming ${ }^{23}$. 
Tabel 2. Contoh kasus dengan menggunakan FMEA

\begin{tabular}{|c|c|c|c|c|}
\hline Kasus & $\begin{array}{l}\text { Negara } \\
\text { (tahun) }\end{array}$ & Dampak & Penyebab kegagalan & Tindakan perbaikan \\
\hline $\begin{array}{l}\text { Industri tekstil PT } \\
\text { ZZ ditemukan } \\
\text { banyak produk } \\
\text { cacat }^{16}\end{array}$ & $\begin{array}{l}\text { Brazil } \\
(2013)\end{array}$ & $\begin{array}{l}\text { - Produk tidak } \\
\text { dapat dijual } \\
\text { - Penjualan } \\
\text { terhambat }\end{array}$ & $\begin{array}{l}\text { - Tidak dilakukan } \\
\text { training } \\
\text { - Setiap penyebab } \\
\text { kegagalan dan } \\
\text { dampak tidak } \\
\text { didokumentasi }\end{array}$ & $\begin{array}{l}\text { - Membuat SOP } \\
\text { - Dilakukan training untuk } \\
\text { semua personil } \\
\text { - Mendokumentasikan setiap } \\
\text { masalah dan } \\
\text { penyelesaiannya }\end{array}$ \\
\hline $\begin{array}{l}\text { Penelitian untuk } \\
\text { pengembangan } \\
\text { sistem penyalutan } \\
\text { berlapis diperoleh } \\
\text { ukuran partikel } \\
\text { yang telah disalut } \\
\text { terlalu besar }\end{array}$ & $\begin{array}{l}\text { Jerman } \\
\text { (2017) }\end{array}$ & $\begin{array}{l}\text { Menyebabkan } \\
\text { rasa asam yang } \\
\text { tidak enak di } \\
\text { lidah }\end{array}$ & $\begin{array}{l}\text { - Tekanan udara } \\
\text { atomisasi terlalu } \\
\text { rendah } \\
\text { - Kecepatan } \\
\text { semprotan terlalu } \\
\text { tinggi }\end{array}$ & $\begin{array}{l}\text { - Dilakukan inspeksi dan } \\
\text { pemeliharaan mesin secara } \\
\text { berkala } \\
\text { - Menentukan spesifikasi dan } \\
\text { batas atas ukuran partikel } \\
\text { setiap produksi }\end{array}$ \\
\hline $\begin{array}{l}\text { Ditemukan } \\
\text { kontaminan pada } \\
\text { bahan baku } \\
\text { setelah } \\
\text { dibersihkan pada } \\
\text { pabrik pengolahan } \\
\text { siput } 26\end{array}$ & $\begin{array}{l}\text { Torino } \\
(2013)\end{array}$ & $\begin{array}{l}\text { - Tidak } \\
\text { memenuhi } \\
\text { spesifikasi } \\
\text { - Dapat } \\
\text { membahayak } \\
\text { an keamanan } \\
\text { konsumen }\end{array}$ & $\begin{array}{l}\text { - Alat dan mesin tidak } \\
\text { bersih } \\
\text { - Personil tidak bersih }\end{array}$ & $\begin{array}{l}\text { - Dilakukan training personil } \\
\text { - Sebelum proses dilakukan } \\
\text { pemeriksaan status } \\
\text { kebersihan ruangan, alat, dan } \\
\text { mesin }\end{array}$ \\
\hline
\end{tabular}

Ishikawa diagram juga dikenal sebagai fishbone diagram atau Cause-Effect Analysis². Suatu tindakan dan langkah perbaikan akan lebih mudah dilakuakn jika akar penyebab masalah sudah ditemukan ${ }^{5}$. Manfaat Ishikawa diagram diantaranya mudah dibaca untuk diagram hubungan sebab akibat sehingga orang-orang lebih cenderung menggunakan metode ini, mengetahui penyebab masalah yang berpengaruh, produktivitas meningkat, dan meningkatkan komunikasi internal maupun eksternal ${ }^{13}$.

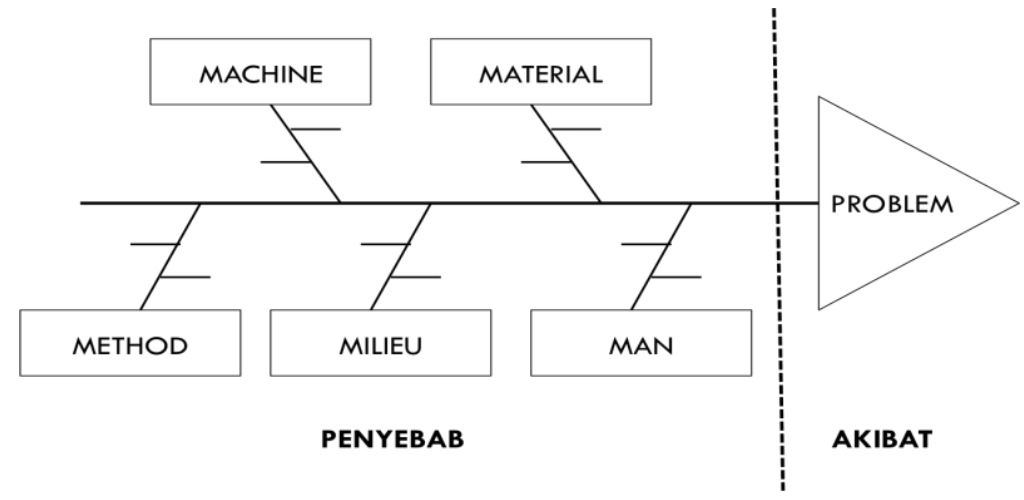

Gambar 1. Ishikawa Diagram ${ }^{13}$ 
Langkah-langkah dalam mengerjakan Ishikawa diagram sebagai berikut ${ }^{11}$ :

1. Tentukan masalah

Masalah diinterpretasikan sebagai akibat. Setiap orang harus memahami dengan jelas sifat masalah dan proses atau produk yang dibahas.

2. Tentukan kategori penyebab utama

Penyebab masalah dikelompokkan ke dalam kategori utama agar dalam menentukan akar penyebab masalah terstruktur. Dalam industri manufaktur umumnya menggunakan kategori 5M yaitu

- Man (manusia): orang-orang yang berkaitan dengan proses

- Methods (metode): bagaimana proses dilakukan dan memenuhi spesifikasi

- Machine (mesin): peratan yang digunakan selama proses

- Materials : bahan baku dan reagen yang digunakan selama proses

- Milieu/Environment (lingkungan): kondisi sekelilingnya selama proses berlangsung

3. Identifikasi terkait penyebab masalah dengan cara brainstorming

Setiap kategori utama memiliki sebab-sebab yang perlu diuraikan melalui brainstorming. Contoh dalam menggunakan Ishikawa diagram sebagai berikut

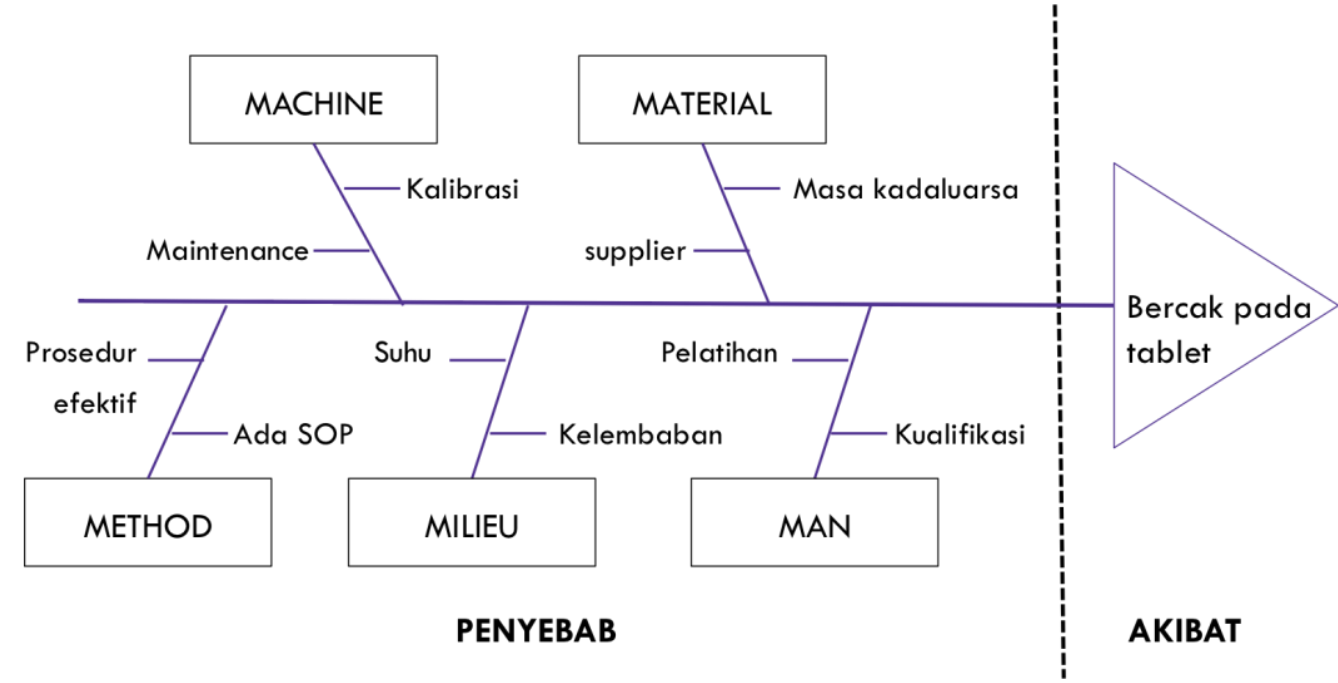

Gambar 2. Contoh penggunaan Ishikawa diagram di industri manufaktur (sumber:

Raman \& Yadavalli, 2019 yang telah dimodifikasi)

4. Analisis diagram

Analisis membantu dalam mengidentifikasi penyebab yang memerlukan investigasi lebih lanjut. Jika terdapat banyak cabang dalam penyebab utama diperlukan investigasi lebih lanjut. Penyebab masalah yang muncul berulang kali berpotensi sebagai akar masalahnya.

Berikut beberapa hasil penggunaan Ishikawa diagram yang ditampilkan dalam Tabel 3 
Tabel 3. Contoh kasus dengan menggunakan ishikawa diagram

\begin{tabular}{|c|c|c|c|c|}
\hline Kasus & $\begin{array}{l}\text { Negara } \\
\text { (tahun) }\end{array}$ & $\begin{array}{l}\text { Kategori } \\
\text { penyeba } \\
\text { b }\end{array}$ & Penyebab utama & $\begin{array}{l}\text { Tindakan } \\
\text { perbaikan }\end{array}$ \\
\hline $\begin{array}{l}\text { Laju } \\
\text { disolusi } \\
\text { tablet } \\
\text { brivanib } \\
\text { tidak } \\
\text { memenuhi } \\
\text { spesiffkasi27 }\end{array}$ & $\begin{array}{l}\text { Amerika } \\
\text { (2019) }\end{array}$ & Material & $\begin{array}{l}\text { - Ukuran partikel } \\
\text { tablet. Semakin } \\
\text { besar ukuran } \\
\text { partikel maka } \\
\text { laju disolusi akan } \\
\text { melambat }\end{array}$ & $\begin{array}{l}\text { - Melakukan } \\
\text { reformulasi untuk } \\
\text { mengecilkan } \\
\text { ukuran partikel } \\
\text { tablet }\end{array}$ \\
\hline $\begin{array}{l}\text { Banyak } \\
\text { ditemukan } \\
\text { tablet } \\
\text { terpisah } \\
\text { (capping) }\end{array}$ & $\begin{array}{l}\text { India } \\
\text { (2009) }\end{array}$ & Mesin & $\begin{array}{l}\text { - Kecepatan mesin } \\
\text { tidak optimal } \\
\text { - Die dan punch } \\
\text { sudah tua } \\
\text { - Granul terlalu } \\
\text { kering }\end{array}$ & $\begin{array}{l}\text { - Dilakukan } \\
\text { pergantian die } \\
\text { dan punch secara } \\
\text { berkala } \\
\text { - Dilakukan } \\
\text { pemeliharan } \\
\text { mesin secara } \\
\text { berkala } \\
\text { - Dilakukan } \\
\text { kalibrasi mesin } \\
\text { dan label kalibrasi } \\
\text { tercantum di alat }\end{array}$ \\
\hline
\end{tabular}

\section{Kesimpulan}

Risiko tidak dapat dihindari dan masalah yang teridentifikasi dapat mengakibatkan menurunnya produktivitas dan kinerja jika tidak dikelola dengan baik. Namun, menggunakan metode dalam manajemen risiko mutu dapat mengendalikan risiko secara efisien. Metode Failure Mode Effect Analysis (FMEA) dan Ishikawa diagram dapat memfasilitasi keputusan yang lebih baik, memberikan jaminan yang lebih besar untuk menghadapi risiko potensial, dan dapat memengaruhi tingkat pengawasan proses maupun produk. Kedua metode ini sering digunakan dalam manajemen risiko karena mudah digunakan.

\section{Daftar Pustaka}

1. Badan Pengawas Obat dan Makanan. 2018. PerKa Badan Pengawas Obat dan Makanan Republik Indonesia No. 34 Tahun 2018 tentang Pedoman CPOB. Jakarta: BPOM RI.

2. Bose, T. K. 2012. Application of Fishbone Analysis for Evaluating Supply Chain and

A CASE STUDY ON THE ST JAMES HOSPITAL International of Managing Value and Supply Chain. 3(2): 17-24. 
3. Chen, Ping-Shun \& Ming-Tsung, Wu. 2013. A Modified Failure Mode and Effect Analysis Method for Supplier Selection Problems in The Supply Selection Problems in The Supply Chain Risk Environment: A Case Study. Computer \& Industrial Engineering. 66(6): 634-642.

4. Dai, Wei., Paul, G. M., Wai, M. C. \& Xiaoqing, Tang. 2011. Decision-making in Product Quality Based on Failure Knowledge. International Journal of Product Lifecycle Management. 5(2): 143-163.

5. Das, Amrita., Praveen, Kadwey., Jai, Kumar Mishra. \& Sudheer, Moorkoth. 2014. Quality Risk Management (QRM) in Pharmaceutical Industry : Tool and Methodolgy. International Journal of Pharmaceutical Quality Assurance. 5(3): 1321.

6. Gough, Pete. 2017. A Beginner's Guide to Quality Risk Management. Pharma Biotech. NSF: UK.

7. lidikó, Mohammed-Zieger., Iddikó, Steff. \& Mária, Halmai-Varényi. 2013. Importance of Quality Risk Management Pharmaceutical Quality System : Recent Trends and Harmonization. Saudi Pharmaceutical Journal.

8. Ilie, Gheorghe \& Carmen, NC. 2010. Application Of Fishbone Diagram To Determine The Risk Of An Event With Multiple Causes. Management Research and Practice. 2(1): 1-20.

9. Khristi, Avani \& Prayerson, Khristi. 2018. A Review on Failure Mode and Effect Analysis - A Tool of Quality Risk Management Based on ICH 9. International Journal of Research in Pharmacy and Chemistry. 8(!): 33-43.

10. Kumar, Nirmal. \& Ajeya, Jha. 2018. Quality risk management during pharmaceutical 'good distribution practices' - A plausible solution. Bulletin of Faculty of Pharmacy Cairo University. 56(1): 18-25.

11. Liliana, Luca. 2016. A New Model of Ishikawa Diagram for Quality Assessment. IOP Conference Series : Materials Science and Engineering.

12. Perera, A. A. A. H. E., \& Navaratne, S. B. 2016. Application of Pareto principle and Fishbone diagram for Waste Management in a Powder Filling Process. International Journal of Scientific \& Engineering Research. 7(11): 181-184.

13. Raman, R. S. \& Yadavalli, Basavaraj. 2019. Quality Improvement of Capacitors through Fishbone and Pareto Techniques. International Journal of Recent Technology and Engineering. 8(2): 2248-2252.

14. Rana, Sourabh \& Belokar, R. M. 2017. Quality Improvement Using FMEA : A Short Review. International Research Journal of Engineering and Technology. 4(6): 263-267.

15. Robin, E., Raymond, J. M. \& Michael, R. B. 2009. The Basic of FMEA. $2^{\text {nd }}$ Edition. CRC Press: New York.

16. Santis, S. H \& João, P. P. 2016. Use of Quality Tools for Problem Analysis (FMEA and Ishikawa Diagram) in a Small Textile Business. Journal of Textile Science and Engineering. 6(3).

17. Shebl, N.A., Bryony, D.F. \& Nick, Barber. 2012. Failure Mode and Effects Analysis Output : Are They Valid?. BMC Health Service Research. 12(150): 1-10. 
18. Simsekler, M. C. E., Gulsum, K. K., James, R. W. \& John, Clarkson. 2019. Evaluating Inputs of Failure Modes and Effects Analysis in Identifying Patient Safety Risks. International Journal Health Care Quality Assurrance. 32(1): 191207.

19. Teoh, P.C. \& Keith, Case. 2014. An Evaluation of Failure Modes and Effect Analysis Generation Method for Concepttual Design. International Journal of Computer Integrated Manufacturing. 18(4): 279-293.

20. Tsai, Sang-Bing., Jie, Zhou., Yang, Gao., Jiangtao, Wang., Guodong, Li., Yuxiang, Zheng., Peng, Ren. \& Wei, Xu. 2017. Combining FMEA with DEMATEL Models to Solve Production Process Problems. PLoS ONE. 12(8): 1-15.

21. WHO. 2012. WHO Guideline on Quality Risk Management. WHO: Switzerland.

22. Wojtaszak, M. \& Bialy, M. 2015. Problem solving techniques as a part of implementation of six sigma methodology in tire production - Case Study. Management System in Production Engineering. 3(19): 133-137.

23. Wong, K.C. 2011. Using an Ishikawa Diagram as A Tool to Assist Memory and Retrieval of Relevant Medical Cases from the Medical Literature. Journal of Medical Reports. 5(120).

24. Xiao, Ningcong., Hong-Zhong, Huang., Yangfeng, Li., Liping, He. \& Tongdan, Jin. 2011. Multiple Failure Modes Analysis and Weighted Risk Priority Number Evaluation in FMEA. Engineering Failure Analysis. 18(4): 1162-1170.

25. Zheng, L.Y., Liu, Q. \& MchMahon, A. 2010. Integration of Process FMEA with Product and Process Design Based on Key Characteristics. 6: 1673-1686

26. Arvanitoyannis, Ioannis \& Theodors H.V. 2009. Application of Failure Mode and Effect Analysis (FMEA) and Cause and Effect Analysis in Conjunction with ISO 22000 to a Snails (Helix aspersa) Processing Plant; A Case Study. Critical Review in Food Science and Nutrition. 49(7): 607-625.

27. Badawy, Sherif., Ajit, S.N., Keirnan, R.L., Ganeshkumar, A.S., Sailesh, A. V., Judy, Lin., Tim, Stevents \& Pankaj, A.S. 2019. Integrated Application of Quality-byDesign Principles to Drug Product and Its Control Strategy Development. Handbook of Pharmaceutical Wet Granulation. Pp 665-702.

28. Paul, S.K. \& Abdullahil, Azeem. 2009. Defect Identification and Analysis Pharmaceutical Product Using Pareto and Cause-Effect Analysis. International Conference on Mechanical Engineering. 